\section{CIDADANIA E ENSINO DE HISTÓRIA NO CURRÍculo OfICIAL DO ESTADO DE SÃo paUlo}

Citizenship and History Teaching in the Official Curriculum of the State of São Paulo
Jorge Eschriqui Vieira PINTO

\author{
(1) jschriqui@yahoo.com.br
}

Universidade Federal

de Goiás

Goiânia, GO, Brasil

\section{Resumo}

Este artigo analisa como a questão da cidadania e possíveis aspectos relacionados a esse tema (a construção de identidades, a diversidade, o direito à memória, a aprendizagem significativa, as práticas avaliativas inclusivas, etc.) repercutem nos princípios norteadores, nos fundamentos para o ensino de História, na metodologia de ensino e aprendizagem, no estabelecimento das competências e habilidades esperadas em cada etapa da vida escolar e na organização dos conteúdos na grade curricular presentes no Currículo do Estado de São Paulo: Ciências Humanas e suas tecnologias para o ensino dessa disciplina na educação básica. Trata-se de uma repercussão relevante no programa curricular devido à sua influência no cotidiano das atividades didáticas desenvolvidas em sala de aula e à importância da disciplina para a constituição da identidade do discente e a sua formação enquanto cidadão atuante e agente transformador da realidade, na medida em que aborda os acontecimentos históricos como resultado das ações de todos os homens e não apenas de "grandes personagens" (governantes, diplomatas, generais etc.), e os direitos políticos, sociais e civis como produto de demandas, negociações, lutas e conquistas de diversos grupos e movimentos sociais ao longo do tempo.

Palavras-chave: Educação, Ensino de História, Curriculo, São Paulo.

\begin{abstract}
This article analyzes how the issue of citizenship and possible aspects related to this theme (the construction of identities, diversity, the right to memory, meaningful learning, inclusive evaluative practices, etc.) have repercussions on guiding principles, teaching of History, teaching and learning methodology, establishing the skills and abilities expected at each stage of school life and the organization of the contents in the curriculum grid present in the State of São Paulo Curriculum: Human Sciences and its technologies for teaching this discipline in basic education. This is a relevant repercussion in the curricular program due to its influence in the daily activities of the didactic activities developed in the classroom and to the importance of the discipline for the constitution of the identity of the student and their formation as an active citizen and transforming agent of reality in the measure which addresses historical events as a result of the actions of all men and not just "big characters" (rulers, diplomats, generals, etc.) and political, social and civil rights as a product of demands, negotiations, struggles and conquests of groups and social movements over time.
\end{abstract}

Keywords: Education, History teaching, Curriculum, São Paulo. 
Há um campo em que desejaria ver muitas demolições, ou pelo menos grandes transformações. Admira-me que não se tenham empregado esforços, no terreno da História, no sentido de se formar uma pedagogia brasileira, pelo menos em relação a alguns de seus aspectos, não só no que se refere à minúcia, como também no que diz respeito ao geral. A minúcia é, sem dúvida, uma das coisas mais importantes, porquanto, todos os dias se toca na realidade que eles encerram. Assim sendo, na viagem histórica para a qual conduzis vossos alunos, não podereis esquecer que eles devam levar alguma bagagem (BRAUDEL, 1955, p. 20).

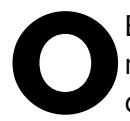

Brasil é um país que viveu um período de vinte e um anos de ditadura militar (1964-1985) e, portanto, pode-se considerar ainda a sua experiência democrática atual como de curta duração. Além disso, trata-se de um regime democrático que não resolveu sérios desafios ao pleno exercício da cidadania, como, por exemplo, problemas na área social, sobretudo no acesso a serviços públicos de qualidade em educação, saúde e saneamento, e no campo dos direitos civis, no que diz respeito à segurança individual. Portanto, apesar de uma ampla gama de direitos presentes na denominada "Constituição Cidadã" de 1988, a cidadania está restrita na prática quase que exclusivamente aos direitos políticos.

O resultado dessa conjuntura é que, passada a euforia da transição democrática dos anos 1980, vive-se uma frustração quanto à expectativa do regime democrático ser capaz de garantir o exercício de uma cidadania plena, ou seja, há o questionamento por uma parcela considerável da população sobre a capacidade das instituições democráticas brasileiras em atentarem para os problemas básicos. Logo, existe uma indagação sobre a eficiência de governos democráticos em garantirem a qualidade da cidadania no Brasil. Neste sentido, seguindo a linha de pensamento de José Murilo de Carvalho, pode-se afirmar que

\begin{abstract}
os progressos feitos são inegáveis mas foram lentos e não escondem o longo caminho que ainda falta percorrer. $O$ triunfalismo exibido nas celebrações oficiais dos 500 anos da conquista da terra pelos portugueses não consegue ocultar o drama dos milhões de pobres, de desempregados, de analfabetos e semianalfabetos, vítimas da violência particular e oficial. Perdeu-se a crença de que a democracia política resolveria com rapidez os problemas da pobreza e da desigualdade (CARVALHO, 2004, p. 219).
\end{abstract}

Exatamente devido a essa conjuntura que o Currículo do Estado de São Paulo: Ciências Humanas e suas tecnologias propõe tornar o ensino de História um instrumento para a consolidação do regime democrático no país, capaz de colaborar para a constituição da identidade dos alunos e prepará-los para o exercício da cidadania, conscientes dos seus direitos e deveres na sociedade e sujeitos ativos na transformação da realidade na medida em que aborda os acontecimentos históricos como resultado das ações de todos os homens e não apenas de "grandes personagens" e os direitos 
políticos, sociais e civis como consequência de lutas, negociações e conquistas de diversos grupos sociais ao longo do tempo. De acordo com esse documento oficial,

\begin{abstract}
os estudantes devem desenvolver um posicionamento crítico frente aos problemas que afetam a vida social, reconhecendo o diálogo como ponto de partida fundamental para a tomada de decisões coletivas. Por conta de nossa formação sóciohistórica, dá-se especial ênfase à questão da identidade: no que se relaciona ao universo social mais amplo da nacionalidade, como no âmbito individual, apontando-se como básico o conhecimento das características fundamentais do Brasil (sociais, materiais e culturais) e o reconhecimento e a valorização da pluralidade que constitui o patrimônio sociocultural brasileiro, assim como o de outros povos e nações. Cabe salientar que essa perspectiva considera o respeito às diferenças que caracterizam os indivíduos e os grupos integrantes da sociedade.

Além desse aspecto, o educando deverá ser capaz de refletir sobre si mesmo, reconhecendo-se como integrante, dependente e agente transformador do ambiente, cuidando para preserválo e assumindo posturas e atitudes de intervenção solidária na sociedade, visando à conquista de níveis elevados de qualidade de vida para si e para o conjunto dos cidadãos (SÃO PAULO, SE, 2012, p. 30).
\end{abstract}

Nesse sentido, o ensino de História é um importante instrumento de combate contra um processo de "amnésia social" e perda de identidade imposto por um mundo globalizado caracterizado por um mercado mundial que tenta estabelecer padrões culturais universais em nome de um consumismo intenso e por um volume enorme de informações e explicações simplistas sobre os acontecimentos por parte dos diferentes meios de comunicação, muitas vezes desvinculadas de uma análise mais profunda da realidade e desconectadas do passado. Segundo Circe Bittencourt,

a escola sofre e continua sofrendo, cada vez mais, a concorrência da mídia, com gerações de alunos formados por uma gama de informações obtidas por intermédio de sistemas de comunicação audiovisuais, por um repertório de dados obtidos por imagens e sons, com formas de transmissão diferentes das que têm sido realizadas pelo professor que se comunica pela oralidade, lousa, giz, caderno e livro, nas salas de aula. No caso da História, as questões se avolumaram à medida que a sociedade consumista tem se estruturado sob a égide do mundo tecnológico, responsável por ritmos de mudanças acelerados, fazendo com que tudo rapidamente se transforme em passado, não um passado saudosista ou como memória individual ou coletiva mas, simplesmente, um passado ultrapassado. Tratase de gerações que vivem o presenteísmo de forma intensa, sem perceber liames com o passado e que possuem vagas perspectivas em relação ao futuro pelas necessidades impostas pela sociedade de consumo que transforma tudo, incluindo o saber escolar, em mercadoria. A História oferecida para as novas gerações é a do espetáculo, pelos filmes, propagandas, novelas, 
desfiles carnavalescos...[...]. O momento atual tem propiciado a introdução de algumas reflexões sobre a necessidade urgente do ofício do historiador e do professor de História no sentido de evitar a amnésia da sociedade atual marcada por incertezas e perspectivas indefinidas (BITTENCOURT, 2006, p. 14).

Contudo, esse mundo globalizado é antagônico, pois, ao mesmo tempo que, do ponto de vista da economia e das relações internacionais, busca incessantemente criar blocos de integração econômica e política (como a União Europeia) e estabelece padrões culturais universais de consumo, ainda é, numa perspectiva humanística e das relações sociais, marcado pela xenofobia, pela intolerância religiosa e racial, por práticas de protecionismo econômico, pelo etnocentrismo e pela resolução de diferenças e conflitos por meio do uso de forças militares. Como o ensino de História pode contribuir para a formação de seres humanos que saibam conviver com as diferenças e façam destas não um fator de intolerância, mas sim de reconhecimento do outro e construção de identidade individual e social? Para o Currículo do Estado de São Paulo: Ciências Humanas e suas tecnologias, a resposta está num ensino dessa disciplina escolar que aborde em sala de aula a noção de alteridade ao longo do tempo, pois é importante que

o estudante desenvolva a consciência de que a convivência social
deve ser alicerçada na percepção e no respeito aos elementos
identitários que caracterizam e diferenciam os indivíduos e os
grupos que compõem a sociedade. Situações históricas para
isso não faltam, envolvendo desde temas mais gerais - como
as relações entre romanos e bárbaros germânicos, europeus e
africanos, europeus e povos americanos ou asiáticos, católicos e
protestantes na Europa do Renascimento - até problemas mais
específicos - como a perseguição histórica aos judeus, desde
a Antiguidade, a questão dos escravos após a independência
dos Estados Unidos da América ou durante a Guerra Civil, as
relações de gênero, a xenofobia e o racismo contemporâneos, a
sexualidade, o imperialismo, etc. (SÃO PAULO, SE, 2012, p. 30-31).

Além disso, esse documento oficial propõe que a noção de alteridade seja trabalhada didaticamente em sala de aula simultaneamente às concepções de diferença, semelhança, transformações e permanências como sugerem os Parâmetros Curriculares Nacionais. Para os PCN, esses quatro conceitos são importantes no processo de ensino e aprendizagem sobre diversas sociedades humanas ao longo da História porque possibilitam ao discente a compreensão de que "a percepção do 'outro' (diferente) e do 'nós' (semelhante) é diversa em cada cultura e no tempo. Ela depende de informações e de valores sociais historicamente construídos” (BRASIL, MEC, 1998a, p. 35).

Dessa maneira, a disciplina História contribui para o aprendizado do relativismo cultural por parte dos discentes, ou seja, de uma atitude de aceitação e respeito pelas culturas, pelas práticas e pelos valores de outros grupos sociais e outras sociedades tanto em uma perspectiva comparativa no presente como em um cotejo entre os 
elementos próprios do tempo presente e os específicos de outros tempos históricos (passado). Observa-se que, para o Currículo do Estado de São Paulo: Ciências Humanas e suas tecnologias, possibilitar o entendimento pelos alunos de práticas e valores de outros tempos, espaços e culturas é um passo fundamental para se evitar o "presenteísmo" da sociedade, construir-se a identidade individual e coletiva do discente e se constituir a cidadania por meio do reconhecimento do outro, retomandose, assim, uma ideia também presente nos PCN de História, sobretudo para o Ensino Fundamental, pois tanto neste como naquele, é claro que

o primeiro objetivo geral é levar os alunos à compreensão da "cidadania como participação social e política. A partir dessa compreensão, espera-se despertar a consciência em relação ao exercício de direitos e deveres políticos, civis e sociais", adotando, "no dia a dia, atitudes de solidariedade, cooperação e repúdio às injustiças, respeitando o outro e exigindo para si o mesmo respeito" (SÃO PAULO, SE, 2012, p. 29-30).

Portanto, há uma preocupação em se analisar nas aulas de História as diversas concepções de cidadania em diferentes sociedades e períodos históricos (democracia ateniense na Grécia Antiga, Roma Antiga, Revolução Inglesa, Revolução Francesa, sociedade contemporânea etc.), mas também em se tornar os conteúdos relacionados (democracia, identidade, direitos políticos, sociais e civis, deveres etc.) a esse recorte temático-conceitual um fator contribuinte para a formação do educando. Em outras palavras, é necessário se abordar o recorte temático-conceitual da cidadania e os conteúdos relacionados a ele de modo que possam ter relevância para a vida atual e futura do aluno, ou seja, para além dos limites da unidade escolar. Durante a operacionalização dessa prática pedagógica,

o professor apresenta e explica conteúdos, organiza situações para a aprendizagem de conceitos, de métodos, de formas de agir e pensar, em suma, promove conhecimentos que possam ser mobilizados em competências e habilidades que, por sua vez, instrumentalizam os alunos para enfrentar os problemas do mundo. Dessa forma, a expressão "educar para a vida" pode ganhar seu sentido mais nobre e verdadeiro na prática do ensino. Se a educação básica é para a vida, a quantidade e a qualidade do conhecimento têm de ser determinadas por sua relevância para vida de hoje e do futuro, para além dos limites da escola (SÃO PAULO, SE, 2012, p. 18).

É nesse aspecto sobre a necessidade da educação básica pública ter como parâmetro para o que ensinar, e com qual qualidade a relevância dos conhecimentos ensinados em sala para a vida do educando para além dos limites do estabelecimento escolar, que o Currículo Oficial do Estado de São Paulo acaba por cair em numa primeira contradição. Se, por um lado, durante o texto do documento, reconhece os conhecimentos das Ciências Humanas e, em especial, da História, como imprescindíveis para a formação humana do educando e seu preparo para o exercício da cidadania, por 
outro, a ênfase do próprio Currículo Oficial em conteúdos relacionados à tecnologia, ao desenvolvimento econômico e à formação de mão de obra técnica a partir da relação entre a obtenção de competências, habilidades e conhecimentos nas escolas, e as exigências do mercado de trabalho (a ideia da capacitação e do ingresso do discente no mercado de trabalho como fator determinante para a aquisição da cidadania), a organização das aulas na grade curricular semanal, sobretudo no Ensino Médio, onde a disciplina possui apenas duas aulas semanais de cinquenta minutos, e o Sistema de Avaliação de Rendimento Escolar do Estado de São Paulo (SARESP), que, entre 2014 e 2017, restringiu-se a avaliações somente nas disciplinas de Língua Portuguesa e Matemática, a partir dos cortes de gastos no orçamento do estado em educação, devido à crise econômica nacional, parecem demonstrar o contrário. Aliás, no que diz respeito ao SARESP, acabou-se contradizendo o Documento Básico das Matrizes de Referência para a Avaliação do SARESP, que, na data de sua publicação, em 2009, afirma que

a avaliação se dará em todas as áreas curriculares, alternando ano a ano a periodicidade delas. Anualmente serão avaliadas as disciplinas Língua Portuguesa e Matemática e, anual e alternadamente, as áreas de Ciências da Natureza (Ciências, Física, Química e Biologia) e Ciências Humanas (História e Geografia). Em 2008, foram avaliadas as disciplinas Língua Portuguesa, Matemática, Ciências, Física, Química e Biologia (SÃO PAULO, SE, 2009, p. 7).

O Currículo Oficial da rede pública estadual de São Paulo, sobretudo no que diz respeito ao Ensino Médio, deixa clara, em sua apresentação, a priorização de um ensino focado mormente nas disciplinas cujos conteúdos estejam mais diretamente relacionados com uma formação que tem em vista um futuro ingresso do discente no mercado de trabalho, inclusive tornando esse fato em elemento condicionante para um pleno exercício da cidadania por parte do estudante no futuro. Para isso, utiliza-se de outro documento oficial, no caso a Lei de Diretrizes e Bases da Educação Nacional (LDBEN, lei n॰ 9394/96), que, no inciso II do artigo 35, estabelece, entre as finalidades do Ensino Médio, "a preparação para o trabalho e a cidadania do educando, para continuar aprendendo, de modo a ser capaz de se adaptar com flexibilidade a novas condições de ocupação ou aperfeiçoamento posteriores” (BRASIL, MEC, 1998b, p. 12). Tomando como base este artigo da LDBEN, o Currículo Oficial do Estado de São Paulo propõe, principalmente para as disciplinas do Ensino Médio, uma articulação entre os conteúdos e o mundo do trabalho como forma de conscientizar o educando sobre a importância do trabalho na sociedade e prepará-lo para o exercício da cidadania plena no futuro por meio de sua inserção no mercado. Portanto, o trabalho

enquanto produção de bens e serviços revela-se como a prática humana mais importante para conectar os conteúdos do currículo à realidade. Desde sua abertura, a LDBEN faz referência ao trabalho, enquanto prática social, como elemento que vincula a educação básica à realidade, desde a educação infantil até a conclusão do Ensino Médio. O vínculo com o trabalho carrega vários sentidos que precisam ser explicitados. 
Do ponto de vista filosófico, expressa o valor e a importância do trabalho. À parte qualquer implicação pedagógica relativa a currículos e à definição de conteúdos, o valor do trabalho incide em toda a vida escolar: desde a valorização dos trabalhadores da escola e da família até o respeito aos trabalhadores da comunidade, o conhecimento do trabalho como produtor de riqueza e o reconhecimento de que um dos fundamentos da desigualdade social é a remuneração injusta do trabalho. A valorização do trabalho é também uma crítica ao bacharelismo ilustrado, que por muito tempo predominou nas escolas voltadas para as classes sociais privilegiadas. A implicação pedagógica desse princípio atribui um lugar de destaque para o trabalho humano, contextualizando os conteúdos curriculares, sempre que for pertinente, com os tratamentos adequados a cada caso.

Em síntese, a prioridade do trabalho na educação básica assume dois sentidos complementares: como valor, que imprime importância ao trabalho e cultiva o respeito que lhe é devido na sociedade, e como tema que perpassa os conteúdos curriculares, atribuindo sentido aos conhecimentos específicos das disciplinas (SÃO PAULO, SE, 2012, p. 22-23).

Dessa maneira, segundo o Currículo Oficial do Estado de São Paulo, consegue-se trazer os conteúdos escolares o mais próximo possível do cotidiano dos discentes, concretizando-se, assim, o processo pedagógico conhecido como transposição didática', ou seja, a capacidade de se dar sentido aos conhecimentos científicos ensinados e aprendidos nas disciplinas escolares para o aluno, aproximando-os de sua realidade e demonstrando a funcionalidade deles para além de sua vida escolar. Ao mesmo tempo, abre-se a possibilidade de uma conexão entre a aprendizagem de conteúdos disciplinares constituintes de formação geral e os de formação profissional

em que os primeiros encarregam-se das competências básicas, fundamentando sua constituição em conteúdos, áreas ou disciplinas afinadas com a formação profissional nesse ou em outro nível de escolarização. Isso supõe que o tratamento oferecido às disciplinas do currículo do Ensino Médio não seja apenas propedêutico, tampouco voltado estritamente para o vestibular (SÃO PAULO, SE, 2012, p. 24).

Essa questão da relação entre habilidades, competências e conteúdos escolares, cidadania e mercado de trabalho, abordada pelo Currículo Oficial do Estado de São Paulo, é um aspecto do documento que merece uma reflexão mais aprofundada, pois como é possível compatibilizar a escola pública, enquanto um espaço de efetivo exercício da cidadania através da inclusão e do acesso de diversos setores sociais ao conhecimento, sem distinção de classe, raça, necessidades físicas ou mentais, com a lógica do mercado de trabalho regida pela competitividade, hierarquização, seleção e exclusão daqueles indivíduos que não são considerados os melhores? Além disso, tal visão da orientação do que ensinar e aprender no currículo escolar a partir das exigências do mercado do trabalho, das tecnologia e da economia remete em suas 
origens a um modelo educacional do período do regime militar, embora o Currículo Oficial do Estado de São Paulo tente evitar tal vinculação ao afirmar que "a tentativa da LDB (Lei $n^{\circ}$ 5692/71) de unir as duas modalidades, profissionalizando todo o Ensino Médio, apenas descaracterizou a formação geral, sem ganhos significativos para a profissional”. Entretanto, como afirma Miguel Gonzáles Arroyo,

tal visão reducionista marcou as décadas de 1970 e 1980 como hegemônica e ainda está presente e persistente na visão que muitas escolas têm de seu papel social e na visão que docentes e administradores têm de sua função profissional. Sobretudo ainda essa visão dos alunos empregáveis é determinante nos formuladores de políticas de currículo. As reorientações curriculares ainda estão motivadas "pelas novas exigências que o mundo do mercado impõe para os jovens que nele ingressarão". As demandas do mercado, da sociedade, da ciência, das tecnologias e competências, ou a sociedade da informática ainda são os referenciais para o que ensinar e aprender. Se continuarmos vendo os educandos desde a educação infantil e, sobretudo, no Ensino Médio e nas séries finais do Ensino Fundamental como recursos humanos a serem carimbados para o mercado segmentado e seletivo, seremos levados a privilegiar e selecionar as habilidades e competências segundo a mesma lógica segmentada, hierarquizada e seletiva. O ordenamento dos conteúdos por séries, níveis, disciplinas, gradeado e precedente, por lógicas de mérito e sucesso nada mais é do que a tradução curricular dessa lógica do mercado e da visão mercantilizada que nós fazemos dos educandos (GONZÁLES ARROYO, 2007, p. 24).

É importante observar que a visão da orientação do que ensinar e aprender no currículo escolar foi, durante o regime militar, o resultado de um modelo educacional explicado por um contexto específico caracterizado por uma política de segurança nacional e de desenvolvimento econômico. Modelo educacional que levou a uma desvalorização das disciplinas das Ciências Humanas, sobretudo da História e Geografia, que sofreram com a redução de suas cargas horárias de aulas e a criação de disciplinas em sintonia com o projeto de poder do regime militar (Educação Moral e Cívica, Organização Social e Política Brasileira e Estudos Sociais). Apesar da campanha de setores vinculados à educação básica e ao meio acadêmico, sobretudo por meio da Associação Nacional dos Professores de História (ANPUH) e da Associação dos Geógrafos do Brasil (AGB), pelo fim de EMC, OSPB e Estudos Sociais e o reaparecimento da História e Geografia como disciplinas independentes na grade curricular do antigo primeiro grau durante o período de redemocratização do país nos anos 1980, até o presente momento essas duas disciplinas sofrem com uma carga horária reduzida, sobretudo no Ensino Médio. No que diz respeito atualmente à rede pública estadual de ensino de São Paulo, no qual a disciplina de História possui quatro horas semanais de cinquenta minutos cada uma, o professor ainda tem disponibilidade de algum tempo para desenvolver atividades diferenciadas, ou mesmo trabalhar com a recuperação de conteúdos nos quais os alunos apresentam dificuldades. Entretanto, no Ensino 
Médio, com os mesmos conteúdos devendo ser abordados de forma mais aprofundada de acordo com a idade e o grau de desenvolvimento psicológico e intelectual dos alunos, a disciplina só dispõe de duas aulas semanais de cinquenta minutos. Pouco tempo tem o professor para retomar o conteúdo ou trabalhá-lo de maneira mais aprofundada e reflexiva. Enfim, tanto no passado quanto no presente, observa-se a formação humanística geral proporcionada pelas disciplinas das Ciências Humanas sendo colocada num segundo plano, apesar de que uma educação preocupada com a formação humana do discente seja essencial para prepará-lo para a vida em sociedade e o exercício da cidadania, isto é, para a promoção de conhecimentos que possam ser continuamente mobilizados durante a sua existência como instrumentos necessários para uma reflexão crítica e atuação efetiva diante dos problemas da sociedade na qual está inserido. $O$ resultado desse processo é que

\begin{abstract}
uma visão dos alunos como empregáveis tem marcado profundamente as autoimagens docentes - sermos vistos como treinadores e preparadores de mão de obra habilitada nas exigências de mercado -, imagens reducionistas da docência, desmotivadoras. [...]

Se os educandos não passam de capital humano a ser capacitado para as demandas hierarquizadas do mercado e se o currículo se organiza nessa lógica segmentada, os profissionais que trabalham esses conteúdos serão segmentados, hierarquizados e valorizados ou desvalorizados na mesma lógica segmentada e hierarquizada do mercado (GONZÁLES ARROYO, 2007, p. 25).
\end{abstract}

Essa perspectiva representa uma negação à abordagem do trabalho na disciplina de História como um direito social importante para a garantia de um exercício da cidadania por parte do aluno? Absolutamente não, pois o que se questiona é uma visão equivocada e mercantilizada dos estudantes, do conhecimento e da docência no currículo escolar que faz uma relação determinista entre a aquisição e o domínio de competências, habilidades e conteúdos escolares e a empregabilidade futura do discente. Aliás, no contexto do mercado de trabalho atual, não há uma relação direta entre o domínio de competências, habilidades e conteúdos escolares e empregabilidade, uma vez que

estudos nos repetem: "apesar do aumento da escolarização, a inserção dos mais pobres no mercado de trabalho está praticamente desaparecendo"; "para os mais jovens das camadas médias cada vez está mais distante a certeza de que uma escola de qualidade Ihes garantirá um emprego de qualidade em um mercado de trabalho tão inseguro" (GONZÁLES ARROYO, 2007, p. 25).

O que o currículo escolar deve ter como princípio norteador para a abordagem da questão do trabalho é que tal tema não pode ser restrito ao ensino e à aprendizagem de competências, habilidades e conteúdos tendo como critério de seleção destes essencialmente as demandas do mercado de trabalho. Uma abordagem alternativa sobre essa questão nos currículos escolares seria enfatizar a realidade atual e de 
outras épocas do mundo do trabalho, percebendo-se como ocorreram simultaneamente ao longo da História o processo de desenvolvimento dos meios de produção e da tecnologia e as lutas de movimentos políticos e sociais por melhores condições de trabalho e vida, possibilitando-se, assim, uma compreensão do direito social ao trabalho como resultado de lutas, negociações e conquistas históricas para a ampliação da cidadania.

Embora o Currículo Oficial do Estado de São Paulo na sua apresentação geral para todas as disciplinas possua a visão equivocada acima citada da orientação do que ensinar e aprender a partir das exigências do mercado do trabalho, por outro lado, apresenta a abordagem alternativa também referida acima no currículo específico da disciplina de História quando, por exemplo, ao tratar dos conteúdos sobre "Revolução Industrial inglesa" e "A luta por direitos sociais no século XIX (Socialismo, comunismo e anarquismo)" para o $3^{\circ}$ bimestre da $2^{a}$ série do Ensino Médio, estabelece como habilidades a serem trabalhadas pelo professor com o aluno em sala de aula:

- Reconhecer a importância da divisão do trabalho para o processo de Revolução Industrial.

- Identificar o significado e as consequências da divisão do trabalho para o trabalhador industrial.

- Reconhecer que os processos de formação e transformação das instituições político-sociais são resultado de lutas coletivas.

- Reconhecer a importância dos movimentos sociais pela melhoria das condições de vida e trabalho ao longo da história.

- Identificar os principais conceitos do ideário dos movimentos revolucionários europeus do século XIX e suas influências nas posições político-partidárias da atualidade (SÃO PAULO, SE, 2012, p. 67).

Essa mesma abordagem pedagógica da disciplina de História sobre direito social ao trabalho também pode ser estendida a outras formas essenciais de garantia de uma cidadania mais ampla, como, por exemplo, o acesso aos direitos políticos e civis. Se há muito conhecimento histórico sobre a cidadania e os direitos sociais, políticos e civis, por que não ampliar o acesso dos alunos ao saber sobre as diferentes concepções de cidadania e as lutas, negociações e conquistas em torno dos direitos sociais, políticos e civis por parte de vários setores em diferentes sociedades ao longo da História? Trata-se de saberes sobre direitos e cidadania que estão diretamente relacionados à realidade vivenciada pelos discentes, devendo ser incluídos com destaque nos currículos escolares como uma forma de garantir o direito ao aluno de acesso a um conhecimento crítico e reflexivo sobre a realidade local, regional, nacional e mundial caracterizada por violações dos direitos humanos, regimes políticos autoritários, desigualdades sociais e econômicas, xenofobia, intolerância religiosa e racial etc. O Currículo Oficial do Estado de São Paulo para a disciplina demonstra essa preocupação com o papel social da História ao estabelecer o estudo do passado não por ele mesmo, mas como forma de compreender a realidade do tempo presente, identificando as possíveis permanências e rupturas (relação entre passado e presente). Um exemplo 
dessa perspectiva pode ser observado quando esse documento oficial estabelece para o conteúdo sobre "Revolução Francesa e expansão napoleônica", a ser tratado no $2^{\circ}$ bimestre do $8^{\circ}$ ano do Ensino Fundamental, que se trabalhe em sala de aula as seguintes habilidades:

- Identificar os principais valores propugnados pela Declaração dos Direitos do Homem e do Cidadão, de 1789, estabelecendo relações entre sua formulação e o contexto histórico em que foi produzida.

- Identificar as principais influências da Declaração dos Direitos do Homem e do Cidadão, de 1789, nas formas características das sociedades contemporâneas.

- Identificar os principais conceitos necessários à compreensão da Revolução Francesa (sociedade estamental, burguesia, nobreza, Antigo Regime, lluminismo, revolução burguesa, Constituição, Assembleia Constituinte, sufrágio universal, cidadania, direitos humanos e liberalismo).

- Identificar, na sociedade contemporânea, práticas e situações de desrespeito aos direitos humanos (SÃO PAULO, SE, 2012, p. 50).

Essa perspectiva do ensino de História presente no Currículo do Estado de São Paulo: Ciências Humanas e suas tecnologias reforça o que é afirmado nos Parâmetros Curriculares Nacionais (PCN) para o Ensino Médio - Parte IV - Ciências Humanas e suas tecnologias, segundo os quais, a área das Ciências Humanas no currículo escolar tem como objetivo exatamente estudar os seres humanos em suas múltiplas relações, devendo os seus saberes serem mobilizados na escola de modo a auxiliar os estudantes na aquisição de conhecimentos que os levem a uma posição reflexiva e crítica sobre os vários problemas da sociedade em que estão inseridos e que afetam diretamente as suas condições de existência e perspectivas de vida. De acordo com os PCN para o Ensino Médio,

uma educação de caráter humanista, capaz de fazer frente aos desafios da contemporaneidade, não pode dispensar a contribuição das Ciências Humanas e da Filosofia para a compreensão das complexas relações sociais e culturais instituídas a partir do impacto das novas tecnologias. [...]

Cabe às Ciências Humanas e à Filosofia colaborar com uma formação básica que assegure a cada um a possibilidade de se construir como ser pensante e autônomo, dotado de uma identidade pessoal referida tanto à dimensão local da sociedade brasileira, com suas especificidades e temporalidades concretas e específicas, quanto à dimensão mundializada (BRASIL, MEC, 1998b, p. 67).

No que diz respeito especificamente à História, os PCN para o Ensino Médio afirmam que essa disciplina possibilita a aquisição de uma bagagem de conhecimentos que poderão ser mobilizados ao longo da vida do aluno e contribuirão para que ele 
possa compreender as relações entre diferentes sociedades no espaço e no tempo, contribuindo para a construção de sua identidade e o reconhecimento do outro, e analisar os inúmeros problemas da sociedade em que vive por meio das relações entre passado, presente e futuro, das noções de permanência e ruptura e dos conceitos de curta (acontecimento), média (conjuntura) e longa duração (sistema). Essa identidade individual e coletiva do discente pode ser construída com a contribuição do ensino da História por meio do estudo de vários grupos sociais, das sociedades e de suas culturas ao longo do tempo, fazendo com que as diferenças sejam vistas não como elementos de preconceitos ou intolerância, mas de aceitação e respeito pelas culturas, pelas práticas e pelos valores deles. Dessa maneira, o reconhecimento do "outro" (diferente) e a busca no passado de elementos identitários (do "nós") do grupo social ou da sociedade nos quais o aluno possa estar inserido (semelhante) tornam-se passos fundamentais em sua formação para o exercício da cidadania. Para que esse processo de ensino e aprendizagem sobre a identidade e o reconhecimento do outro aconteça em sala de aula, o professor de História deve estimular

o aluno para a reflexão sobre o outro, discutindo a alteridade e a sua própria escola - ou nem tanto, como nos acontecimentos internacionais. O tema é áspero e difícil de ser incorporado por qualquer aluno do ensino fundamental ou médio. No entanto, a discussão sobre o outro, sobre as diferenças e semelhanças podem e devem ser feitas pelo professor. Os assuntos que servirão como ponto de partida são muitos, mas o professor não pode abdicar dessa discussão sobre o outro. Falar do mundo islâmico ou cristão, do mundo rural ou urbano, de comunidades indígenas ou das megalópoles ou ainda da era tecnológica é estabelecer um local de enunciação para se discutir sobre as diferenças. [...]

O professor de História pode articular seus conteúdos para que o aluno visualize a expressão de preconceitos e como eles surgem ou podem ser analisados em diversos instantes da História. Ele não dará lições, mas apresentará reflexões sobre as diferentes sociedades e grupos culturais, como eles se relacionaram entre si, com a necessidade de sobrevivência e a articulação da produção. Apresentará as diferenças culturais, étnicas, de gênero, suas implicações em sistemas políticos e ideológicos, os papéis da religião a composição do imaginário, o impacto da tecnologia, as inclusões e exclusões que se associam a elas etc. (FREITAS NETO, 2016, p. 69-70).

O Currículo do Estado de São Paulo: Ciências Humanas e suas tecnologias afirma que o ensino de História pode contribuir para a construção da identidade individual e coletiva dos estudantes a partir de práticas pedagógicas que estimulem um estudo comparativo entre hábitos, costumes, valores e práticas culturais de indivíduos, grupos e sociedades em diferentes tempos históricos, observando-se, assim, os elementos de diferenciação ou aproximação entre eles e se aprendendo a conviver respeitosamente com a diversidade de grupos, culturas, valores, interesses e identidades. Portanto, a diversidade deve ser percebida pelos discentes não como um fator propagador da 
intolerância, do preconceito e do conflito, mas como algo importante para a percepção de elementos comuns no grupo local, na população nacional e em outros povos distantes no espaço e no tempo capazes de criarem uma identidade individual e coletiva. Afinal, a maneira como se vive, a visão de mundo, as técnicas de produção, o vestuário e modo de se estabelecerem as relações sociais, além de outros aspectos culturais, fazem parte de um legado histórico dos antepassados, criando-se laços de identidade entre o presente e as gerações passadas, que, inclusive, podem ser fatores norteadores das ações dos alunos como cidadãos conscientes da realidade e de seus limites e suas capacidades de intervenção nela para transformá-la. Segundo o Currículo Oficial do Estado de São Paulo para a disciplina de História,

o desafio para quem trabalha com História consiste em extrair conhecimento de vestígios e fragmentos da humanidade que sobreviveram à passagem do tempo e a outras distâncias. Constrói-se, assim - a partir do presente, como ensinou Benedetto Croce -, uma espécie de ponte intelectual que pode nos levar aos lugares de onde viemos para saber o que e quem somos e, principalmente, o que poderíamos ser, já que um dos principais compromissos da cultura histórica é com a constante reelaboração estética do mundo social, movendo-se sempre na contramão do esquecimento (SÃO PAULO, SE, 2012, p. 28-29).

A partir dessa citação, constata-se uma preocupação desse documento oficial com o conhecimento histórico enquanto elemento essencial para a construção da identidade individual e coletiva. Entretanto, ao mesmo tempo, há a constatação da necessidade de que esse conhecimento não se fundamente apenas na ação de grandes heróis, em detrimento de outros sujeitos históricos, relegando-se ao esquecimento as camadas populares, sobretudo os segmentos étnicos indígena e negro. Tratando-se o Brasil de uma nação cuja formação social é multirracial, é importante que se dê voz aos diversos segmentos sociais e étnicos que contribuíram para a constituição histórica da sociedade brasileira. Nesse sentido, o Currículo Oficial do Estado de São Paulo está em sintonia com a Lei de Diretrizes e Bases da Educação Nacional (LDBEN, lei no 9394/96), que enfatiza a importância da valorização da diversidade cultural da formação histórica brasileira como condição indispensável para a construção de uma escola plural e cidadã. Estabelece essa lei, no artigo 26-A, que "nos estabelecimentos de ensino fundamental e de ensino médio, públicos e privados, torna-se obrigatório o estudo da história e cultura afro-brasileira e indígena (Redação dada pela Lei no 11.645, de 2008)", e no parágrafo $4^{\circ}$, do mesmo artigo, que "o ensino da História do Brasil levará em conta as contribuições das diferentes culturas e etnias para a formação do povo brasileiro, especialmente das matrizes indígena, africana e europeia". Essa consonância entre os dois documentos oficiais pode ser observada, por exemplo, quando o Currículo do Estado de São Paulo: Ciências Humanas e suas tecnologias estabelece que, ao abordar os conteúdos "Sociedades indígenas no território brasileiro", "O encontro dos portugueses com os povos indígenas" e "Tráfico negreiro e escravismo africano no Brasil", nos $3^{\circ}$ e $4^{\circ}$ bimestres do $7^{\circ}$ ano do Ensino Fundamental, o professor de História estimule o desenvolvimento das seguintes habilidades nos alunos: 
- Reconhecer a importância do estudo das questões de alteridade para compreender as relações de caráter históricocultural.

- Reconhecer e valorizar a diversidade dos patrimônios etnoculturais e artísticos, identificando-a com em suas manifestações e representações ao longo da História.

- Relacionar a ocupação do território brasileiro ao longo da História à transformação e/ou destruição das sociedades indígenas.

- Identificar as principais características e consequências das relações ampliadas ou estabelecidas entre os europeus e os povos de outros continentes, como África, Ásia e América.

- Identificar as principais características do trabalho escravo no engenho açucareiro e nas minas.

- Identificar as formas de resistência dos africanos e afrodescendentes visando à extinção do trabalho escravo, com ênfase para os quilombos.

- Reconhecer que a formação das sociedades contemporâneas é resultado de interações e conflitos de caráter econômico, político e cultural (SÃO PAULO, SE, 2012, p. 46-47).

O Currículo Oficial do Estado de São Paulo também demonstra uma preocupação em estimular a formação de uma cultura política de valorização do Estado Democrático de Direito a partir do ensino de História, principalmente durante a abordagem de conteúdos como o nazifascismo, a Segunda Guerra Mundial, a ditadura militar e a redemocratização no Brasil, no $9^{\circ}$ ano do Ensino Fundamental e na $3^{a}$ série do Ensino Médio. A ideia desse documento é superar uma prática pedagógica tradicional que tende a transformar o ensino de História apenas numa memorização de conteúdos desconectados da realidade cotidiana dos discentes e sem um papel social. Desse modo, propõe-se que a disciplina tenha a função social de contribuir para a formação de hábitos, valores e comportamentos políticos de crítica a regimes autoritários e totalitários e de valorização da democracia. Afinal, não se nasce cidadão, mas, sim, forma-se com uma prática cotidiana de estudo, compreensão e intervenção na realidade por meio da participação política e uma conscientização de que o exercício da cidadania implica em direitos e deveres. Como afirma Jaime Pinsky, a cidadania não é

uma concepção abstrata, mas uma prática cotidiana. Ser cidadão não é simplesmente conhecer, mas, sim, viver. Não há possibilidade de ser cidadão em um regime totalitário, como a Alemanha de Hitler, a Itália de Mussolini ou uma nação latino-americana submetida a governos militares. Isso não significa, contudo, que a democratização formal transforme, automaticamente, todos os habitantes do país em cidadãos. Costuma-se dizer que a cidadania, como a liberdade, não pode ser outorgada, mas, sim, conquistada. Se isso é verdadeiro, não é menos verdadeiro que cabe a nós, educadores, um papel fundamental no sentido de ampliar o debate sobre a questão da cidadania e os limites impostos à sua prática. Uma boa maneira de fazê-lo seria meditarmos um pouco sobre a dificuldade que 
encontramos para exercer plenamente a nossa cidadania e sobre as barreiras que impedem a sua prática. Podemos dizer que muitas das dificuldades têm a ver com a nossa própria História, com a maneira como a Nação brasileira surgiu e como ela se articula com o Estado. De fato, em nosso país, o Estado precedeu a Nação, ao contrário do que ocorreu em outros países. Em 1822, estabeleceu-se como instituição jurídica o Estado brasileiro sem que houvesse ainda uma Nação brasileira. Em outras palavras, cria-se uma instituição jurídica sem a existência da correspondente base social (PINSKY, 1999, p. 96).

Dessa maneira, o currículo torna-se "o instrumento mais poderoso de intervenção do Estado no ensino, o que significa sua interferência, em última instância, na formação da clientela escolar para o exercício da cidadania" (ABUD, 2006, p.28). Paralelamente, a História vive uma situação contraditória, pois ao mesmo tempo que se encontra desvalorizada como outras Ciências Humanas na grade curricular da rede pública estadual de ensino, em decorrência de uma visão do que ensinar e aprender determinada por exigências do mercado de trabalho, da tecnologia e da economia, por outro lado, é uma disciplina estratégica para o Estado para a definição do tipo de cidadão almejado. Segundo Selva G. Fonseca,

os professores de História sujeitos do processo vivenciam uma situação extremamente complexa e ambígua: trata-se de uma disciplina que é ao mesmo tempo extremamente valorizada, estratégica para o poder e a sociedade e ao mesmo tempo desvalorizada pelos alunos e por diversos setores do aparato institucional e burocrático (FONSECA, 2011, p. 70).

Para o Currículo do Estado de São Paulo: Ciências Humanas e suas tecnologias, o conhecimento histórico é fundamental para a constituição de uma cidadania caracterizada pela crítica às experiências políticas autoritárias e totalitárias do passado e do presente, pela valorização do Estado Democrático de Direito, por um protagonismo responsável e capaz de transformar a realidade. Isto é notório quando se analisa as habilidades propostas a serem desenvolvidas nos $3^{\circ}$ e $4^{\circ}$ bimestres do $9^{\circ}$ ano do Ensino Fundamental, quando se trabalha os conteúdos sobre "Populismo e ditadura militar no Brasil" e "Redemocratização no Brasil":

- Estabelecer relações entre a Guerra Fria e os golpes militares na América Latina.

- Reconhecer a importância dos movimentos coletivos e de resistência para as conquistas sociais e a preservação dos direitos dos cidadãos ao longo da História.

- Caracterizar os governos militares instalados no Brasil a partir de 1964, considerando especialmente a supressão das liberdades e a repressão à oposição.

- Identificar os principais movimentos de resistência aos governos militares, até a deflagração da campanha das "Diretas Já". 
- Estabelecer relações entre a supressão da censura à imprensa e o processo de redemocratização do Brasil.

- Reconhecer os principais movimentos rurais e urbanos de contestação aos sistemas políticos e econômicos ao longo da História.

- Reconhecer que o processo histórico não decorre apenas da ação dos chamados grandes personagens (SÃO PAULO, SE, 2012, p. 57-58).

Ademais, é fundamental que sejam trabalhadas as questões do reconhecimento da importância do direitos humanos ao longo da História e do exercício de direitos e deveres como aspectos necessários para a preparação do aluno para a convivência em um Estado Democrático de Direito e a prática da cidadania. Um exemplo dado a essa proposta pedagógica pelo Currículo Oficial do Estado de São Paulo está nas habilidades estabelecidas para os conteúdos do $1^{\circ}$ bimestre da $3^{a}$ série do Ensino Médio sobre "Imperialismos, Gobineau e o racismo" e "Nazismo e racismo":

- Analisar criticamente as justificativas ideológicas apresentadas pelas grandes potências para interferir nas várias regiões do planeta (sistemas modernos de colonização, imperialismo, conflitos atuais).

- Relacionar o princípio de respeito aos valores humanos e à diversidade sociocultural, nas análises de fatos e processos histórico-sociais.

- Reconhecer alternativas de intervenção em conflitos sociais e crises institucionais que respeitem os valores humanos e a diversidade sociocultural.

- Identificar as principais características dos regimes totalitários.

- Discutir situações da vida cotidiana relacionada a preconceitos étnicos, culturais, religiosos e de qualquer outra natureza.

- Reconhecer a importância de aplicar os conteúdos aprendidos na escola a intervenções solidárias na realidade, com o objetivo de garantir o respeito aos valores humanos (SÃO PAULO, SE, 2012, p. 69).

Uma vez reconhecida a importância estratégica do ensino de História para a preparação do aluno para a vida civil, um desafio a ser enfrentado na educação básica é um certo desinteresse dos estudantes pela área de Ciências Humanas decorrente da resistência à leitura. A disciplina de História pode contribuir para a solução desse problema educacional, desde que os professores reflitam sobre quais fatores de ordem social e cultural podem ser apontados como explicativos para a prática de resistência à leitura. Além disso, mais do que refletirem sobre tais questões, os docentes devem rever seus próprios hábitos de leitura e buscar práticas pedagógicas que incentivem os estudantes a ler.

Portanto, não é por acaso que o Currículo Oficial do Estado de São Paulo, em sua apresentação para todas as disciplinas, cita como um de seus princípios estruturais 
o "currículo que tem como prioridade a competência leitora e escritora", ou seja, a necessidade da abordagem dos conteúdos tratados em sala de aula a partir de uma problematização fundamentada na leitura e produção de textos. Segundo esse documento, essa competência da leitura e escrita é

\begin{abstract}
parte integrante da vida das pessoas e está intimamente associada ao exercício da cidadania. As práticas de leitura e escrita, segundo as pesquisas que vêm sendo realizadas na área, têm impacto sobre o desenvolvimento cognitivo do indivíduo. Essas práticas possibilitam o desenvolvimento da consciência do mundo vivido (ler é registrar o mundo pela palavra, afirma Paulo Freire), propiciando aos sujeitos sociais a autonomia na aprendizagem e a contínua transformação, inclusive das relações pessoais e sociais.

Nesse sentido, os atos de leitura e de produção de textos ultrapassam os limites da escola, especialmente os da aprendizagem em língua materna, configurando-se como prérequisitos para todas as disciplinas escolares. A leitura e a produção de textos são atividades permanentes na escola, no trabalho, nas relações interpessoais e na vida. Por isso mesmo, o Currículo proposto tem por eixo a competência geral de ler e de produzir textos, ou seja, o conjunto de competências e habilidades específicas de compreensão e de reflexão crítica intrinsecamente associado ao trato com o texto escrito (SÃO PAULO, SE, 2012, p. 15-16).
\end{abstract}

No que diz respeito especificamente à História, a disciplina pode possibilitar o desenvolvimento da capacidade de leitura, reflexão e escrita por meio da interpretação contextualizada de documentos históricos. Esse procedimento implica em destacar no aluno a consciência de que o conhecimento histórico é o resultado de uma construção metodológica e não um saber acabado ou verdade absoluta. Desse modo, os discentes podem analisar, através dos discursos presentes nos documentos, os sujeitos históricos que os produziram, as intencionalidades e os significados que deram para os diferentes fatos históricos.

Ao se fazer essa iniciação histórica do aluno, tem-se como objetivo não a formação profissional dele na disciplina, mas induzi-lo a um processo de reflexão sobre uma determinada realidade e à compreensão de como o conhecimento produzido sobre essa realidade foi construído. Contudo, é importante ressaltar que o trabalho com a interpretação de documento em sala de aula não deve ter uma função apenas ilustrativa ou de reforço da narrativa histórica e dos conceitos apresentados no livro didático e/ou no caderno do aluno. Pelo contrário, a ideia é possibilitar ao estudante a percepção de que o documento fala e que o faz conforme as perguntas são feitas a ele, constituindo-se tanto em objeto de pesquisa histórica como manifestação do ponto de vista sobre a realidade de um sujeito atuante em seu tempo. Entre os possíveis questionamentos a se levantar durante o trabalho pedagógico de leitura crítica e reflexiva de documentos com os alunos nas aulas de História, podem-se citar os seguintes: O que é o documento? Quem o fez, quando o fez, em nome de quem, 
com quais propósitos? Qual é a relação do documento no contexto de sua produção com a realidade mais ampla a que se quer chegar? Esse método crítico de trabalho com os documentos históricos em sala de aula é imprescindível, pois

\begin{abstract}
em nossa época, mais que nunca exposta às toxinas da mentira e do falso rumor, que escândalo o método crítico não figurar nem no menor cantinho dos programas de ensino! Pois ele deixou de ser apenas o humilde auxiliar de alguns trabalhos de oficina. Doravante vê abrirem-se diante de si horizontes bem mais vastos: e a História tem o direito de contar entre suas glórias mais seguras ter assim, ao elaborar sua técnica, aberto aos homens um novo caminho rumo à verdade e, por conseguinte, àquilo que é justo (BLOCH, 2001, p. 124).
\end{abstract}

Em outras palavras, a leitura crítica e reflexiva por parte do discente leva à conclusão por parte dele de que o documento não é um fornecedor de dados prontos ou espelho fiel de uma realidade, mas um discurso produzido por um determinado sujeito histórico que busca, através de uma dada construção narrativa do passado, construir uma determinada memória histórica. Dessa maneira, o aluno desperta em si a consciência de que ele não é um mero receptáculo de conteúdos acabados, mas um agente reflexivo e produtor de seu conhecimento durante o processo de ensino e aprendizagem. Portanto, a História

\begin{abstract}
deve funcionar como instrumento capaz de levar o aluno a perceber-se como parte de um amplo meio social. Assim, mesmo partindo das relações mais imediatas, por meio do estudo da História, o aluno poderá compreender as determinações sociais, temporais e espaciais presentes na sociedade. Por isso, recomenda-se que o desenvolvimento de capacidades de leitura, reflexão e escrita - objetivo central deste programa curricular - parta de situações cotidianas, para avaliar as influências históricas (portanto, sociais e culturais) que condicionam as formas de convivência coletiva. A História funcionaria, assim, como uma espécie de espelho do tempo, mostrando imagens que, embora intangíveis, vão sendo desenvolvidas pela curiosidade de cada observador em busca do conhecimento (SÃO PAULO, SE, 2012, p. 36).
\end{abstract}

A disciplina de História tem muito a contribuir para a formação de um cidadão com senso crítico, desde que o professor não se restrinja a aulas expositivas que tornam o aluno apenas consumidor de um conhecimento pronto e acabado, mas que trabalhe com leitura, reflexão e escrita de textos e enxergue o estudante como um sujeito ativo no processo de ensino e aprendizagem, ou seja, alguém que é capaz plenamente de se posicionar, discutir, tomar a palavra e questionar os pressupostos que lhe foi dito ao longo dos conteúdos curriculares trabalhados em sala de aula. Além disso, o professor deve desenvolver práticas pedagógicas que estimulem a aquisição pelos alunos de conteúdos, conceitos e formas de pensar e agir que os conduza à percepção de que 
as reflexões de natureza histórica realizadas em sala de aula não são importantes apenas para a vida escolar, mas são apenas um ponto de partida que servirá para outras reflexões de natureza semelhante ao longo de toda a existência deles. Afinal, dentro ou fora do ambiente escolar, o estudante continuará sendo sempre um indivíduo eminentemente histórico, sendo as suas ações e formas de pensamento influenciadas pelo conjunto de valores, hábitos, atitudes e comportamentos que estão em voga na sociedade da qual pertencem em um determinado tempo e espaço.

Finalmente, um aspecto que também merece uma análise no Currículo Oficial do Estado de São Paulo diz respeito à contradição entre um ensino público que se pauta pela preocupação com a inclusão de alunos provenientes de camadas sociais mais baixas e de estudantes portadores de necessidades especiais na escola, garantindo-se, assim, o direito social do acesso à educação, e o ordenamento dos conhecimentos, da avaliação e das didáticas a partir dos parâmetros das competências e habilidades a serem aprendidas pelos alunos a cada bimestre, série ou ano. De acordo com o Currículo do Estado de São Paulo: Ciências Humanas e suas tecnologias,

a organização dos conteúdos escolares está sinteticamente apontada em tópicos disciplinares e objetivos formativos e será em seguida detalhada em termos de habilidades a ser desenvolvidas em associação com cada tema, por série/ano e bimestre letivo, ou seja, em termos do que se espera que os estudantes sejam capazes de fazer após cada um desses períodos (SÃO PAULO, SE, 2012, p. 37).

Não seria um equívoco se pensar numa escola pública como espaço de formação para o exercício da cidadania e inclusão social e que, ao mesmo tempo, adota a lógica classificatória dos estudantes em níveis "avançado", "básico" e "abaixo do básico" do documento básico do Sistema Avaliação do Rendimento Escolar do Estado de São Paulo (SARESP), baseada na capacidade de se acompanhar os tempos e ritmos de aprendizagem esperados oficialmente? Não se poderia constituir tal classificação em instrumento de rotulação e, consequentemente, em fator de desestímulo e evasão escolar por parte daqueles estudantes que apresentam tempos e ritmos de aprendizagem diferentes daqueles estabelecidos pelos documentos oficiais? Para Paulo Freire, "formar é muito mais do que puramente treinar o educando no desempenho de destrezas" (FREIRE, 2002, p. 15).

O problema de um currículo baseado em parâmetros ideais de tempos e ritmos de aprendizagem é que

as competências e habilidades, que deverão ser aprendidas e em que tempos e ritmos, por bimestres, séries, níveis, têm como referente os alunos vistos como os mais capazes, sem problemas de aprendizagem, os acelerados, não-defasados, bem sucedidos. [...] 
Tudo na escola é pensado para esse padrão de normalidade ou de aluno desejado: os conteúdos e o seu ordenamento, as provas, os tempos e ritmos de aprendizagem. Aluno padrão a partir do qual serão avaliados os "outros" alunos. Os dados revelam que altas porcentagens de alunos que não atingem esse padrão de normalidade são classificados como incapazes, fracassados, lentos, deficientes (GONZÁLES ARROYO, 2007, p. 30).

A partir desta colocação de Miguel G. Arroyo, podem-se fazer outros questionamentos: como compatibilizar o ideal de uma escola inclusiva e cidadã, que respeita as diferenças a partir do pressuposto de que os alunos apresentam ritmos e tempos diferentes de aprendizagem, com um currículo que adota um parâmetro de aprendizagem de competências e habilidades a partir de um tipo de estudante considerado ideal? Isso invalidaria qualquer tentativa de estabelecimento de uma referência para a avaliação da qualidade de aprendizagem dos conteúdos presentes no currículo oficial? Portanto, o grande desafio da rede pública de educação básica do Estado de São Paulo é, ainda que reconhecendo a importância da existência das competências e habilidades como referências necessárias para o estabelecimento de um padrão mínimo de qualidade no ensino e na aprendizagem dos conteúdos comuns a todos os alunos da rede, que tais parâmetros não sejam fatores de rotulação, exclusão e evasão dos alunos com defasagens e/ou ritmos e tempos de aprendizagens. É necessário, sim, que tais parâmetros sejam utilizados por sistemas de avaliações externas, como o SARESP, para o apontamento de falhas e correções na rede pública de educação básica do estado, propiciando ao governo estadual o investimento adequado, por exemplo, na melhoria das estruturas físicas das escolas para torná-las mais atraentes e estimuladoras para a aprendizagem dos alunos, na melhoria da formação dos docentes, em um plano salarial e de carreira correto que estimule a permanência e a dedicação exclusiva do servidor à Secretaria de Educação e o respeito e reconhecimento profissional da sociedade etc. Em outras palavras, é indispensável não confundir medição com avaliação, pois

avaliar é um processo em que realizar provas e testes, atribuir notas ou conceitos é apenas parte do todo. A avaliação é uma atividade orientada para o futuro. Avalia-se para tentar manter ou melhorar nossa atuação futura. Essa é a base da distinção entre medir e avaliar. Medir refere-se ao presente e ao passado e visa obter informações a respeito do progresso efetuado pelos estudantes. Avaliar refere-se à reflexão sobre as informações obtidas com vistas a planejar o futuro. Portanto, medir não é avaliar, ainda que o medir faça parte do processo de avaliação (FERNANDES, 2007, p. 19).

É contraditório que os critérios de competências e habilidades usados para estabelecer o que oficialmente se espera dos alunos ao longo do processo de ensino e aprendizagem dos diferentes conteúdos de História também sirvam para classificar os estudantes perante as capacidades de aprender, resultando na categorização daqueles que têm tempos e ritmos de aprendizagem fora do padrão considerado ideal como 
"abaixo do básico". É notório que atualmente se propõe, do ponto de vista teórico e metodológico, uma produção científica e um ensino de História que sejam inclusivos e considerem todos os indivíduos, e não apenas os "grandes personagens", como sujeitos ativos nas transformações históricas das sociedades em diversos tempos e espaços. Então, seria congruente se pensar num currículo para a disciplina de História que limitasse o acesso ao ensino público (direito essencial para o exercício de uma cidadania social) e, consequentemente, atrapalhasse a possibilidade de alunos que têm maiores dificuldades de aprendizagem de se tornarem agentes transformadores de sua história e de seu meio social? Adotando-se tal postura,

os hierarquizados como desiguais na sociedade continuarão vistos e tratados como desiguais nas escolas. [...] Poderíamos ter outra postura: reconhecer que a sociedade cria desiguais e, não obstante, como profissionais do conhecimento e dos processos mentais de aprendizagem, partir de onde as ciências partem: de que toda mente humana é igualmente capaz de aprender. [...]. Os desiguais por classe, raça, etnia são vistos como desiguais nas capacidades e ritmos de aprendizagem dos conteúdos ou do conhecimento socialmente construído. É preocupante que, por décadas, continuemos incapazes ou com medo de questionar nosso olhar que classifica os alunos como desiguais perante as capacidades de aprender. Como é preocupante que o ordenamento dos conteúdos e sua gestão tenha por parâmetro as mentes tidas como as mais capazes e aceleradas, as mentes "normais", e avalie a todos por esse parâmetro excludente, tido como democrático (GONZÁLES ARROYO, 2007, p. 31).

O Currículo Oficial do Estado de São Paulo propõe iniciativas para acelerar a aquisição das competências e habilidades esperadas durante o ensino dos diversos conteúdos por parte dos alunos com tempos e ritmos de aprendizagem diferentes, tais como a recuperação paralela e contínua e a progressão contínua para o $7^{\circ}$ e $8^{\circ}$ anos do Ensino Fundamental. Contudo, até que ponto essas estratégias compensatórias adotadas para com estes alunos são suficientes para resolver uma lógica classificatória dos alunos a partir de parâmetros considerados ideais sobre o desenvolvimento cognitivo por ano/série e bimestre, rotulando-os de "avançado", "básico" e "abaixo do básico"? Não estariam apenas reforçando essa lógica, "já que por natureza são menos capazes, lentos, desacelerados, tentemos minimizar essas incapacidades mentais acelerando seus ritmos lentos"? (GONZÁLES ARROYO, 2007, p. 32).

As competências e habilidades não seriam parâmetros curriculares controversos por trazerem dentro de si classificações de caráter excludente e desigual que não condizem com uma escola inclusiva e preocupada com uma cidadania social, medindo e separando os estudantes a partir de uma referência do que seria o aluno ideal capaz de aprender os conteúdos previstos nos tempos e ritmos almejados no currículo? Em caso de resposta afirmativa,

por que não os questionar? Por que há tantas resistências a questioná-lo? Esses parâmetros se tornaram inquestionáveis, 
como que os sagrados símbolos da qualidade da educação. Em nome deles, negamos o direito à educação e ao conhecimento a percentagens altíssimas de crianças e adolescentes, de jovens e adultos, sobretudo dos setores populares e dos educandos com necessidades especiais. Os milhões de analfabetos que passaram pelas escolas, os 32 milhões que não completaram os anos iniciais da Educação Básica, os quase $70 \%$ de defasados idade-série, os milhões de jovens e adultos que voltam à EJA a refazer percursos escolares truncados, os milhões de "deficientes" excluídos da escola. Todos vítimas do mesmo parâmetro escolar: terem sido julgados incapazes de aprender os conteúdos previstos, nos tempos e ritmos previstos nos currículos (GONZÁLES ARROYO, 2007, p. 33).

Esse artigo não teve a pretensão de esgotar o tema da cidadania no ensino de História presente no Currículo Oficial do Estado de São Paulo, mas promover reflexões e indagações sobre esse assunto para o debate no meio acadêmico a partir de estudos pessoais e da experiência enquanto professor de educação básica na rede pública estadual de ensino. Trata-se de um tema fundamental para adequar-se o ensino da disciplina à demanda da sociedade brasileira atual por uma contínua consolidação do Estado Democrático do Direito (o que passa pelo conhecimento do passado e do presente para não se cometer os mesmos equívocos de certos períodos da história nacional e mundial, marcados pela violação de direitos fundamentais, sobretudo em sociedades que passaram pela experiência de regimes autoritários e totalitários), observar-se a importância da participação política de diversos setores e movimentos sociais e políticos nas lutas, negociações e conquistas de direitos políticos, sociais e civis, e criar-se memórias e identidades individuais e coletivas a partir do estudo comparativo de culturas e sociedades em diversos tempos e espaços. 


\section{Referências}

BITTENCOURT, C. "Capitalismo e cidadania nas atuais propostas curriculares de História". In: BITTENCOURT, C. O saber histórico na sala de aula. 11a. ed. São Paulo: Contexto, 2006, p. 11-27.

BLOCH, M. L. B. Apologia da História ou o ofício do historiador. Trad. André Telles. Rio de Janeiro: Zahar, 2001.

BRASIL. Lei de Diretrizes e Bases da Educação Nacional. Disponível em: http://www. planalto.gov.br/ccivil_03/leis/L9394.htm. Acesso em: 14 janeiro 2018.

BRASIL. Ministério da Educação e do Desporto. Secretaria de Educação Fundamental. Parâmetros Curriculares Nacionais. Brasília: MEC/SEF, 1998a.

BRASIL. Ministério da Educação e do Desporto. Secretaria de Educação Média e Tecnológica. Parâmetros Curriculares Nacionais (Ensino Médio) - Parte IV - Ciências Humanas e suas tecnologias. Brasília: MEC/SEMT, 1998b.

BRAUDEL, F. Pedagogia da História. Revista de História-USP, São Paulo, v. XI, n. 23, p. 3-21, 1955.

CARVALHO, J. M. de. Cidadania no Brasil: o longo caminho. 5a. ed. Rio de Janeiro: Civilização Brasileira, 2004.

FERNANDES, C. O. Indagações sobre currículo: currículo e avaliação. Brasília: Ministério da Educação, Secretaria de Educação Básica, 2007.

FONSECA, S. G. Didática e prática de ensino de História: experiências, reflexões e aprendizados. 12a. ed. Campinas: Papirus, 2011.

FREIRE, P. Pedagogia da autonomia: saberes necessários à prática educativa. 23a ed. São Paulo: Paz e Terra, 2002.

FREITAS NETO, J. A. de. "A transversalidade e a renovação no ensino de História". In: Karnal, L. História na sala de aula: conceitos, práticas e propostas. 6a. ed. São Paulo: Contexto, 2016, p. 57-74.

GONZÁLES ARROYO, M. Indagações sobre o currículo: educandos e educadores: seus direitos e o currículo. Brasília: MEC/SEB, 2007.

PAIS, L. C. "Transposição didática”. In: MACHADO, S. D. A. Educação Matemática. Uma (nova) introdução. 3a. ed. São Paulo: EDUC, 2015, p. 11-48.

PINSKY, J. Cidadania e educação. 3a. ed. São Paulo: Contexto, 1999.

SÃO PAULO. Secretaria de Educação. Currículo do Estado de São Paulo: Ciências Humanas e suas tecnologias. São Paulo: SE, 2012.

SÃO PAULO. Secretaria de Educação. Matrizes de referência para a avaliação SARESP - documento básico. São Paulo: SE, 2009. 


\section{Nota}

${ }^{1}$ Transposição didática é o processo pedagógico de seleção e adaptação dos conhecimentos produzidos no meio científico/acadêmico e difundidos nas instituições escolares por meio dos conteúdos curriculares das diversas disciplinas de acordo com o nível de desenvolvimento cognitivo em cada série/ano e faixa etária e a realidade vivenciada cotidianamente pelos alunos. Desse modo, ocorre a transformação dos saberes científicos em saberes escolares por meio do trabalho pedagógico e das atividades didáticas sugeridas pelos programas curriculares e adotadas pelos docentes na educação básica, possibilitando-se uma aprendizagem significativa dos conteúdos curriculares por parte dos discentes. Para Luiz Carlos Pais, "no desenvolvimento de toda prática educativa é sempre necessário estabelecer prioridades na condução dos procedimentos pedagógicos. Uma dessas prioridades diz respeito à seleção dos conteúdos que constituem os programas escolares. O conjunto desses conteúdos, que também pode ser chamado de saber escolar, tem como fonte original o saber científico. Entretanto, através dos efeitos de todo um processo evolutivo, ocorrem transformações que acabam determinando características bem particulares ao saber escolar. A noção de transposição didática visa estudar esse processo seletivo que ocorre através de uma longe rede de influências envolvendo diversos segmentos do sistema educacional” (PAIS, 2015, p. 16). O termo transposição didática foi desenvolvido pelo pesquisador e professor francês em Metodologia e Didática de Ensino de Matemática do Institut Universitaire de Formation des Maîtres de l'Académie d'Aix-Marseille, Yves Chevallard, aparecendo pela primeira vez na obra La Transposition Didactique, de 1985.

Jorge Eschriqui Vieira Pinto é Bacharel e Licenciado em História na Universidade de Brasília. Realizou Especialização em Metodologia do Ensino de História e Docência e Gestão da Educação Básica na Faculdade UnyLeya. Mestre e Doutor em História pela Universidade Estadual Paulista Júlio de Mesquita Filho. Atualmente faz Pós-Doutorado no Programa de Pós-Graduação em História da Universidade Federal de Goiás, linha de Pesquisa em Fronteiras, Interculturalidades e Ensino de História. 